Research article

urn:1sid:zoobank.org:pub:51E7D466-5ABE-458B-ACAF-C83CA975BB97

\title{
A new genus and three new species of jumping spiders (Araneae: Salticidae) from Sri Lanka
}

\author{
Nilani KANESHARATNAM ${ }^{1}$ \& Suresh P. BENJAMIN ${ }^{2, *}$ \\ ${ }^{1,2}$ National Institute of Fundamental Studies, Hantana Road, Kandy, Sri Lanka. \\ *Corresponding author: suresh.benjamin@gmail.com \\ 1Email: nilanik4@yahoo.com \\ ${ }^{1}$ urn:1sid:zoobank.org:author:2C782F97-2700-4B4F-94EC-B21F1D890DB6 \\ ${ }^{2}$ urn:lsid:zoobank.org:author:986CED51-9425-4CB6-84A4-A9464BB9207E
}

\begin{abstract}
A new genus of jumping spiders, Bavirecta gen. nov. is proposed to include the type species B. flavopuncta gen. et sp. nov. and Bavirecta exilis (Cao et al., 2016) gen. et comb. nov. Distinguishing characters of Bavirecta gen. nov. include: 1) tubular abdomen, 2) enlarged front legs, 3) straight and pointed embolus, broadest proximal lobe with black blotches, 4) prolateral tegular lobe, 5) widely separated anterior atria. Furthermore, two new species, Schenkelia aurantia sp. nov. ( ${ }^{1}+$ ) and Brancus calebi (ठ) sp. nov., are described and diagnosed. Mogrus frontosus (Simon, 1871) is redescribed based on a male collected from Mandaitivu Island of Jaffna District in Sri Lanka. The genera Brancus Simon, 1902, Mogrus Simon, 1882 and Schenkelia Lessert, 1927 are reported for the first time from Sri Lanka (Brancus and Schenkelia are recorded for the first time outside Africa).
\end{abstract}

Keywords. Biodiversity, new record, taxonomy, India, South Asia.

Kanesharatnam N. \& Benjamin S.P. 2018. A new genus and three new species of jumping spiders (Araneae: Salticidae) from Sri Lanka. European Journal of Taxonomy 444: 1-24. https://doi.org/10.5852/ejt.2018.444

\section{Introduction}

The jumping spider fauna of Sri Lanka is remarkably diverse, harbouring 86 species placed in 50 genera, 12 tribes and 5 subfamilies (World Spider Catalog 2018), with a large endemic component. Recent fieldwork conducted around the country suggests that this might only be a small fraction of the island's jumping spider biodiversity. Descriptions of most of the currently known species are 'old' nominal descriptions that lack illustrations. However, this picture has progressively been changing with several 'new' descriptions of salticid taxa (Benjamin 2004, 2006, 2010, 2015; Benjamin \& Kanesharatnam 2016; Edwards \& Benjamin 2009; Kanesharatnam \& Benjamin 2016). The main goal of the present study is to add to this body of data by describing/redescribing several taxa, either new to science or new to the island's biota.

Salticidae mostly consists of several polyphyletic genera comprising heterogeneous groupings of unrelated species (Maddison 2015; Prószyński 2017). Thus, there is a pressing need to revise most 
genera with the goal of erecting monophyletic species groups (Maddison 2015). However, such large-scale revisionary studies, though desirable, are difficult to achieve and time consuming. In the meantime, biodiversity loss - human induced or otherwise - continues unabated. This paper describes several endemic taxa with the goal of broadening our knowledge of them and eventually aiding their conservation.

\section{Material and methods}

Methodology and taxonomic descriptions are based on the format of Benjamin \& Kanesharatnam (2016) and Kanesharatnam \& Benjamin (2016). Sampling was primarily done by beating vegetation up to a height of approximately $1.5 \mathrm{~m}$. Collected specimens were preserved in $70 \%$ and/or $100 \%$ ethanol for further study. An Olympus SZX7 stereo microscope was used for the identification of spiders. Female genitalia were excised and digested with the Sigma Pancreatin LP 1750 enzyme complex; male palps and epigynes were cleared and mounted with methyl salicylate for examination (Alvarez-Padilla \& Hormiga 2008; Dingerkus \& Uhler 1977). An Olympus BX51 microscope with attached drawing tube was used for drawings of male palps, epigynes and vulva. A Nikon D80 camera with a macro lens was used to image live spiders. Photographs of palps, epigynes and intact spiders were taken with a Leica MC170 HD camera mounted on a Leica M205C stereo microscope using Leica Application Suite software (Leica Microsystems Limited, Germany). Images were merged with Helicon Focus image stacking software (v. 6, Helicon Soft Ltd), edited with Adobe Photoshop CC and assembled using Adobe Illustrator CS6. All measurements are in millimeters.

\section{Abbreviations}

Morphology:

$\mathrm{AEB}=$ anterior epigynal border

$\mathrm{AL}=$ abdominal length

ALE $=$ anterior lateral eyes

ALT = apical lobe of tegulum

$\mathrm{AME}=$ anterior median eyes

$\mathrm{AT}=$ atrium

$\mathrm{ATR}=$ atrial rim

AW $=$ abdominal width

$\mathrm{CD}=$ copulatory ducts

$\mathrm{CO}=$ copulatory opening

$\mathrm{E} \quad=$ embolus

$\mathrm{Fm}=$ femur

$\mathrm{FD}=$ fertilization ducts

$\mathrm{Mt}=$ metatarsus

PEB $=$ posterior epigynal border

$\mathrm{PL}=$ prosoma length

PLE $=$ posterior lateral eyes

PLT = proximal lobe of tegulum

$\mathrm{PME}=$ posterior median eyes

$\mathrm{Pt}=$ patella

$\mathrm{PW}=$ prosoma width

RTA = retrolateral tibial apophysis

$\mathrm{S}=$ spermathecae

$\mathrm{SD}=$ sperm duct

$\mathrm{Ta}=$ tarsus

$\mathrm{Tb}=$ tibia 


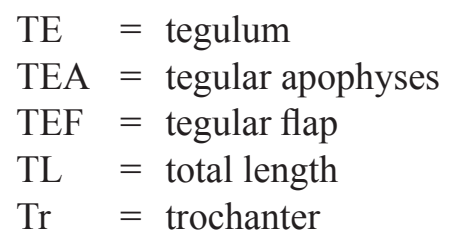

\section{Institutions:}

DFC = Department of Forest Conservation, Colombo, Sri Lanka

DWLC $=$ Department of Wildlife Conservation, Colombo, Sri Lanka

NIFS = National Institute of Fundamental Studies, Kandy, Sri Lanka

ZFMK = Zoological Research Museum Alexander Koenig, Bonn, Germany

\section{Results}

Family Salticidae Blackwall, 1841

Subfamily Salticinae Blackwall, 1841

Bavirecta gen. nov. urn:1sid:zoobank.org:act:3B4C0F4B-CD7C-4D26-BE01-73FB44D46193

\section{Type species}

Bavirecta flavopuncta gen. et sp. nov.

\section{Diagnosis}

Bavirecta gen. nov. resembles other Baviini (Bavia Simon, 1877, Piranthus Thorell, 1885, Stagetilus Simon, 1885), some Viciriini Simon, 1901 and some Marpissina Simon, 1901 by the flattened body form, broad oval prosoma, tubular abdomen and enlarged front legs (Maddison 2015). However, it can readily be distinguished from them by the following combination of characters: prosoma dorsally with a lighter trapezoid (Figs 1A, 3A), comparably long RTA, broad proximal lobe with black blotches (glands, arrow in Fig. 1A), well-developed prolateral lobe of bulbus (Figs 1D-E, 2A-B), small, rounded atrium at anterior portion of epigynum, relatively long copulatory ducts and pear-shaped spermathecae (Figs 2C-D, 3C-D).

\section{Etymology}

A combination of the prefix 'bavi' and the suffix 'recta'. 'Bavi' is taken from Bavia and refers to the Bavia-like appearance of members of the genus. 'Recta' is derived from the Latin, meaning straight, and refers to the orientation of the embolus.

\section{Description}

Large, flattened foliage-dwellers. Prosoma oval, relatively flat, with central lighter trapezoid dorsally (Cao et al. 2016) present in both sexes but more pronounced in females (Figs 1A, 3A). Prosoma broader than abdomen, eye field slightly elevated, sternum oval. Posterior margin of prosoma truncated. Pedicel obscured by anterior portion of abdomen. Abdomen elongated, tubular, broadest anteriorly and narrowing to posterior end with long spinnerets. Dorsum of abdomen with bright yellow or light brown markings (Figs 1A, 3A). First pair of legs much darker than other pairs and more robust, with elongated femur I, patella I and tibia I. Tibia I with ventral spines in two rows of three each, metatarsi I with 2-2 ventral spines on distal half (Cao et al. 2016). Embolus medium sized, straight and pointed, with or without retrolateral membranous margin, tegulum with broad posterior lobe with black blotches and well-developed prolateral lobe; RTA curved ventrally, medium-sized, slightly shorter than tibia 
(Figs 1C-E, 2A-B). Epigynum with a pair of small, rounded atria at anterior portion and $\mathrm{CD}$ with thick wall, spermathecae shape variable (Figs 2C-D, 3C-D).

\title{
Distribution
}

China, Sri Lanka.

\author{
Bavirecta flavopuncta gen. et sp. nov. \\ urn:1sid:zoobank.org:act:8A0B5608-6893-4BBF-A776-B1A1B75F49EE
}

Figs $1-3$

\section{Diagnosis}

Bavirecta flavopuncta gen. et sp. nov. is sister to B. exilis gen. et comb. nov. They share the presence of the following characters: straight and pointed embolus, broad proximal lobe with black blotches and well-developed prolateral tegular lobe (Cao et al. 2016). However, B. flavopuncta gen. et sp. nov. is distinguishable from $B$. exilis gen. et comb. nov. by the comparably broader embolus, absence of the retrolateral membranous margin of the embolus, straight RTA (Figs 1C-E, 2A-B) and the blackish brown abdomen with bright yellow markings in both sexes (Figs 1A, 3A).

Furthermore, due to the short, straight embolus, broad PLT and widely separated anterior atria, this new species may resemble some members of Bavia (B. aericeps Simon, 1877, B. capistrata (C.L. Koch, 1846), B. intermedia (Karsch, 1880)). However, all species of Bavia differ from Bavirecta gen. nov. by their comparably very short RTA.

\section{Etymology}

The species name is from the Latin terms, 'flavo' and 'puncta' and refers to the yellowish brown semicircular markings behind the PLEs.

\section{Material examined}

Holotype

SRI LANKA: §̊, Central Province, Kandy District, Dunumadalawa Forest, hand collection, 7 Oct. 2009, S.P. Benjamin, R.M.G.N. Tilakarathna and P.M.H. Sandamali leg. (IFS_SAL_340).

\section{Paratype}

SRI LANKA: , Central Province, Kandy District, Corbett's Gap, Knuckles Range, 1360 m, 07021'40" N, $80^{\circ} 50^{\prime} 00^{\prime \prime}$ E, hand collection, 12 Aug. 2010, S.P. Benjamin \& S. Batuwita leg. (IFS_SAL_679).

\section{Description}

\section{Male}

MEAsurements. TL 5.1, PL 2.15, PW at PLEs 1.65, AL 2.85, AW 1.00. Eye field: diameter of AME 0.70, PLE 0.16, ALE 0.32, PME 0.03, PME-PME 1.62, PLE-PLE 1.51, ALE-PME 0.41, ALE-PLE 0.73. Leg I: Tr 0.35, Fm 2.00, Pt 0.90, Tb 2.00, Mt 1.40, Ta 0.85; Leg II: Tr 0.35, Fm 1.15, Pt 0.45, Tb 1.05, Mt 0.80, Ta 0.40; Leg III: Tr 0.35, Fm 1.15, Pt 0.60, Tb 0.85, Mt 0.75, Ta 0.35; Leg IV: Tr 0.45, Fm 1.25, Pt 0.55, Tb 1.10, Mt 0.95, Ta 0.40.

COLOR AND BODY. In preserved specimens, prosoma oval, flattened and dark reddish brown interspersed with grey hairs. Anterior prosoma narrower than posterior region. Ocular field decorated with two light brown blotches behind AMEs and a large, light brown semicircular marking behind PLEs (Fig. 1A). PMEs and PLEs surrounded by black blotches. Fovea distinct. Posterior prosoma rather steep and its margin more truncated. Chelicerae and labium brownish black. Brownish yellow sternum oval in 

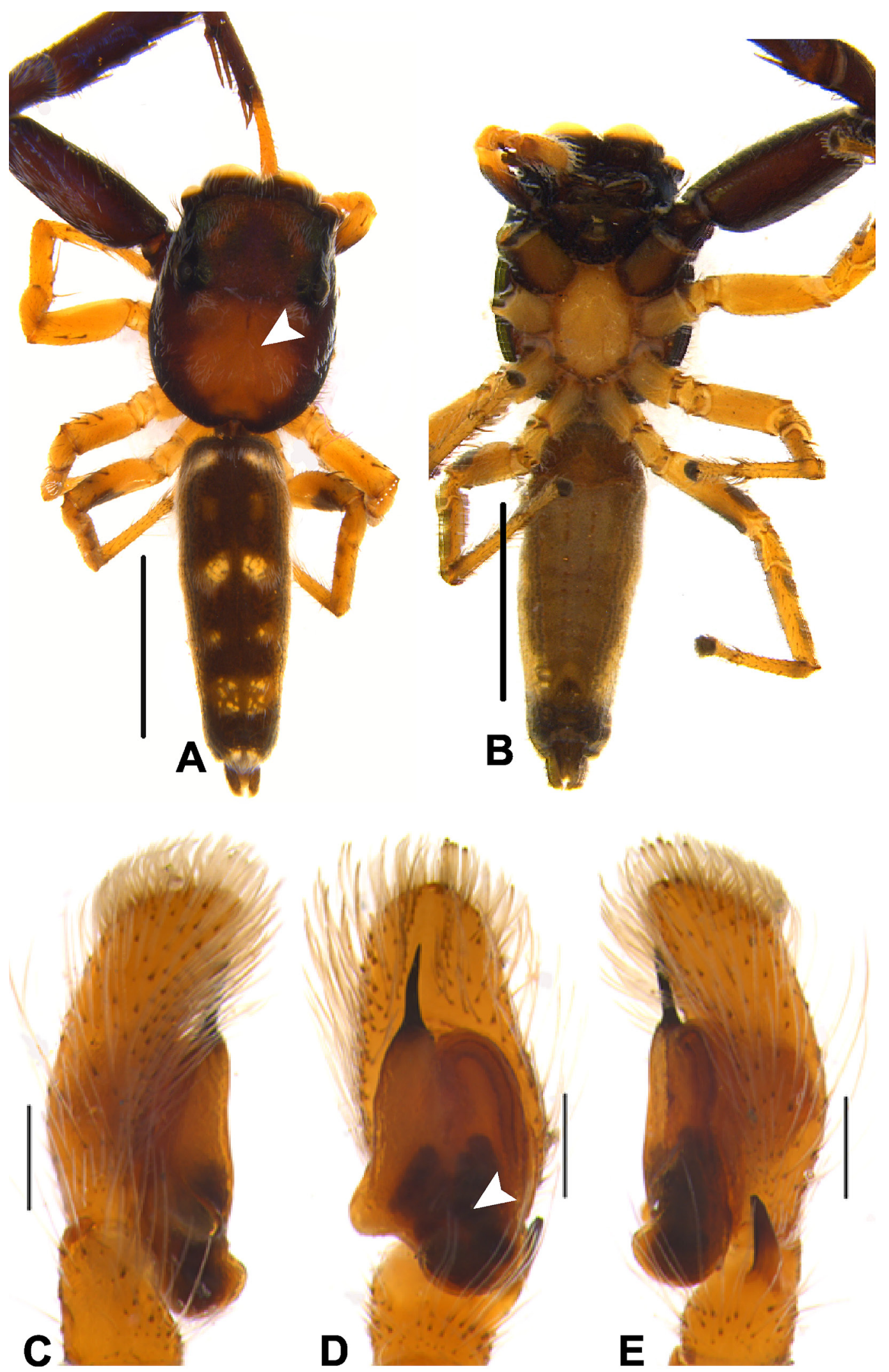

Fig. 1. Bavirecta flavopuncta sp. nov., đ̃. A. Habitus, dorsal view. B. Habitus, ventral view. C. Palp, prolateral view. D. Palp, ventral view. E. Palp, retrolateral view. The arrowheads point to the dorsal trapezoid (A) and black blotches (D). Scale bars: A-B $=2 \mathrm{~mm}$; C-E $=0.2 \mathrm{~mm}$. 

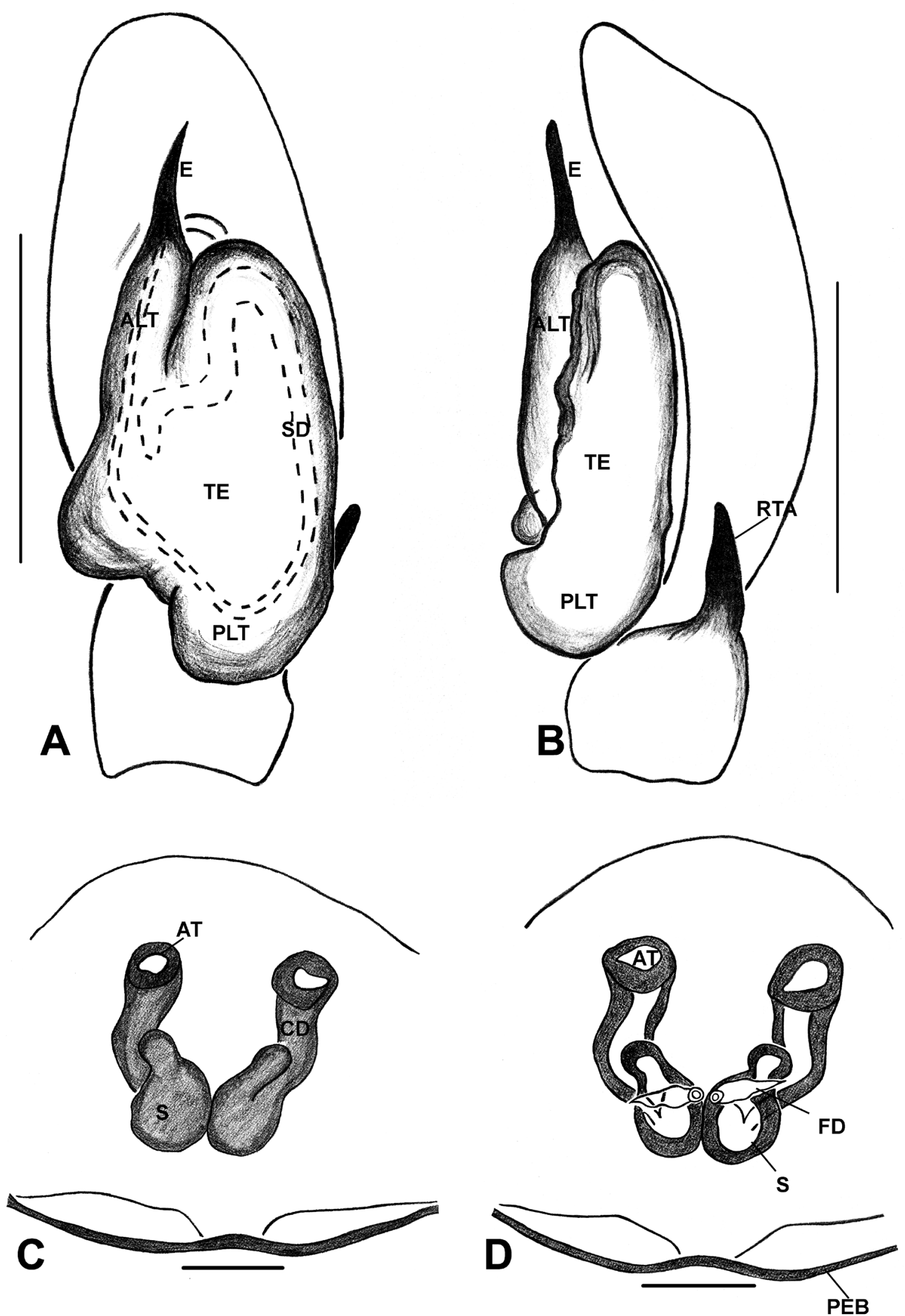

Fig. 2. Bavirecta flavopuncta sp. nov. A. Palp, ventral view. B. Palp, retrolateral view. C. Epigyne, ventral view. D. Vulva, ventral view. Abbreviations: see Material and methods. Scale bars: A-B = $0.2 \mathrm{~mm} ; \mathrm{C}-\mathrm{D}=0.1 \mathrm{~mm}$. 

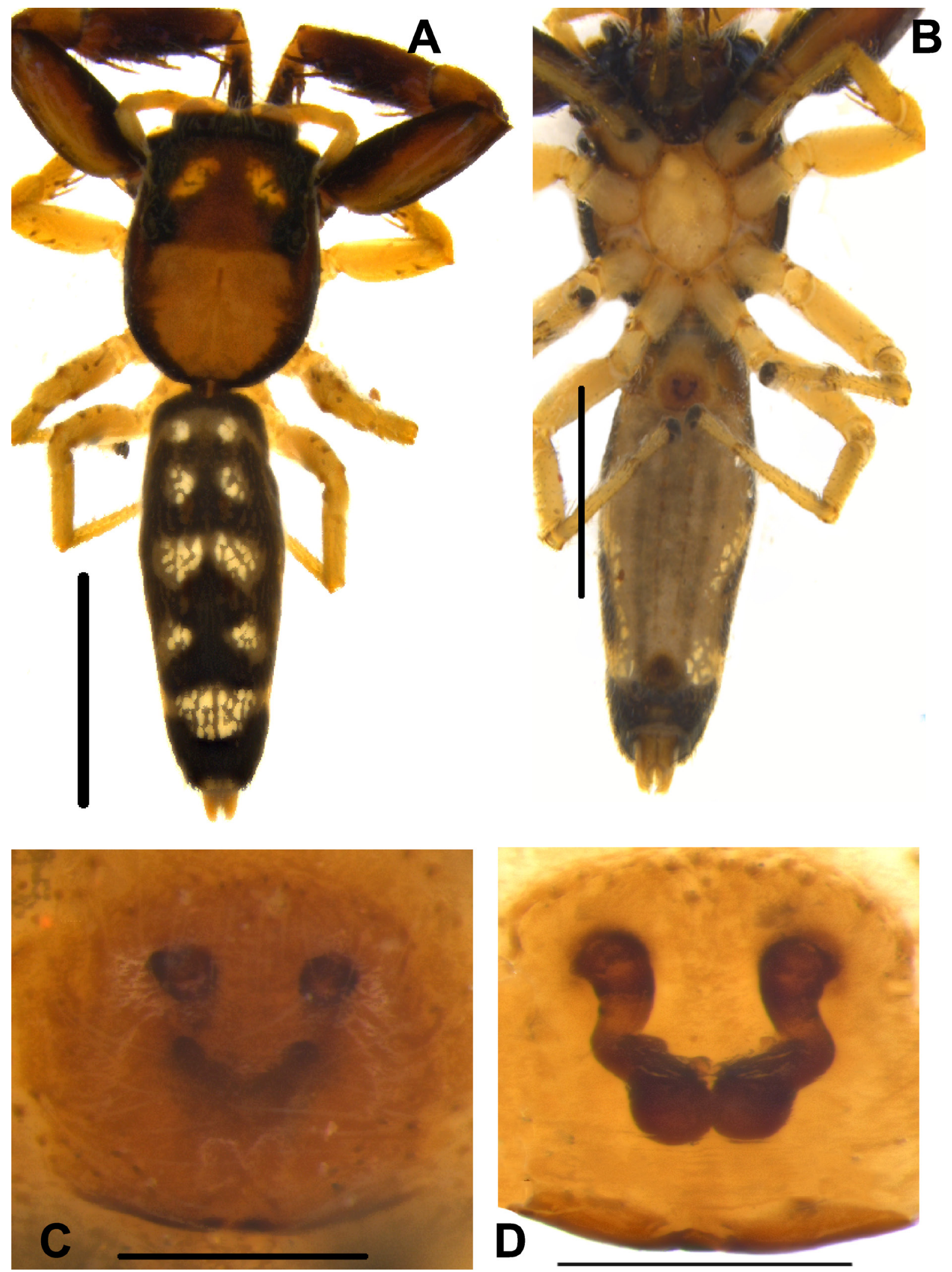

Fig. 3. Bavirecta flavopuncta sp. nov., q. A. Habitus, dorsal view. B. Habitus, ventral view. C. Epigyne, ventral view. D. Vulva, ventral view. Scale bars: A-B $=2 \mathrm{~mm}$; $C-D=0.2 \mathrm{~mm}$. 
shape, edges bordered with fawn colour. Leg I dark brown and robust, femur I, patella I and tibia I massive and more elongated, others brownish yellow and femur IV with black blotches on the lateral sides (Fig. 1A-B). Abdomen much longer and narrower than prosoma, tapering posteriorly. Dorsum, yellowish dark brown ornamented with bright yellow blotches arranged in two rows from anterior to posterior end (Fig. 1A). Venter greyish yellow with brown dash-line from epigastric furrow to brownish black posterior end. Spinnerets yellowish brown (Fig. 1B).

PalP. Pale yellowish brown. Cymbium shorter and slightly narrower at distal region. Embolus robust, pointed, moderately long and immovable on apical portion of bulbus (Figs 1C-E, 2A-B). Bulbus longer than wide. Sperm duct clearly visible in antero-lateral portion of bulbus. Prolateral portion of bulbus with a large protuberance (Figs 1C-D, 2A). Tegulum with broad posterior lobe. RTA moderately long, broader at the base, narrower toward the tip and bent ventrally (Figs 1D-E, 2B).

\section{Female}

Measurements. TL 5.60, PL 2.20, PW at PLEs 1.70, AL 3.25, AW 1.25. Eye field: diameter of AME 0.68, PLE 0.19, ALE 0.32, PME 0.03, PME-PME 1.65, PLE-PLE 1.57, ALE-PME 0.49, ALE-PLE 0.70. Leg I: Tr 0.40, Fm 2.15, Pt 0.95, Tb 2.05, Mt 1.45, Ta 0.85; Leg II: Tr 0.35, Fm 1.25, Pt 0.50, Tb 1.00, Mt 0.90, Ta 0.45; Leg III: Tr 0.40, Fm 1.15, Pt 0.65, Tb 0.95, Mt 0.80, Ta 0.40; Leg IV: Tr 0.40, Fm 1.35, Pt 0.50, Tb 1.2, Mt 1.00, Ta 0.45.

COLOR AND BODY. All characters as in male, except prosoma with more prominent yellowish orange blotches and lateral abdomen with yellow markings as in dorsum (Fig. 3A).

EpIGYNum. Moderately sclerotized. Anterior epigynal border (AEB) not prominent. Small and rounded atrium covered with highly sclerotized ATR into which CO opens (Figs 2C-D, 3C-D). CD highly sclerotized, broad and moderately long. Spermathecae nearly pear-shaped. FD originates from midlateral wall of receptacles (Figs 2D, 3D). PEB highly sclerotized and elongated beyond epigastric furrow.

Bavirecta exilis (Cao, Li \& Żabka, 2016) gen. et comb. nov.

Bavia exilis Cao, Li \& Żabka, 2016: 54-56, figs 7-8.

\section{Remarks}

The type species Bavirecta flavopuncta gen. et sp. nov. and B. exilis gen. et comb. nov. are very similar to each other in somatic as well as genital morphology. Both species differ considerably in genital structures from the type species of Bavia, B. aericeps (see discussion below). Bavirecta exilis gen. et comb. nov. shares the presence of a short, straight embolus and the broad PLT with Bavia aericeps, $B$. capistrata and $B$. intermedia. However, it differs from them by the relatively long RTA and the well-developed retrolateral membranous margin of the embolus. Bavirecta exilis gen. et comb. nov. is described in detail and diagnosed in Cao et al. (2016).

Genus Brancus Simon, 1902

\section{Type species}

Brancus muticus Simon, 1902, by original designation.

\section{Diagnosis}

Body with slightly oval or pear-shaped prosoma and elongated narrow abdomen. A pair of tear-shaped spots on the area of fovea (sometimes poorly visible in dark-coloured specimens) is also characteristic (Wesołowska \& Russell-Smith 2011; Wesołowska \& Haddad 2013). In most species, abdomen with 
contrasting pattern of transverse bands or median light band. Chelicerae unidentate. First two pairs of legs substantially stouter and longer than the rest, with numerous spines. Bulbus generally rounded and oval in some species (Wesołowska \& Edwards 2012), characterized by small, triangular flap. Thin and long embolus encircling bulbus partially or fully. Palpal tibia with short- or medium-sized apophysis. Epigyne with sclerotized egigynal grooves which are spiral, with strongly sclerotized flanges (Wesołowska \& Russell-Smith 2011), sometimes partially divided by arches associated with the genital openings. CD simple, spermathecae oval or bent (Prószyński 2016).

\section{Distribution}

These are the first records of the genus for Sri Lanka and India. Brancus was previously only known from Africa.

$$
\begin{gathered}
\text { Brancus calebi } \text { sp. nov. } \\
\text { urn:1sid:zoobank.org:act:71A16523-CB0E-4023-B654-3C46DF092CFE } \\
\text { Figs 4, 5C-D }
\end{gathered}
$$

Thyene bivittata - Caleb \& Mathai 2014: 65, figs 31-37. Misidentification.

\section{Remarks}

Brancus calebi sp. nov. was misidentified and described as Thyene bivittata Xie \& Peng, 1995 by Caleb \& Mathai (2014). However, it differs considerably from T. bivittata as well as from other species of Thyene by the general habitus (see Discussion). Our specimen, a male collected from Ethagala, is conspecific with the Indian specimen illustrated and described as Thyene bivittata in Caleb \& Mathai (2014). We were unable to examine the Indian specimen for further study and confirmation.

\section{Diagnosis}

Brancus calebi sp. nov. can be readily distinguished from its congeners by the finger-shaped membranous outgrowth on the anterolateral position of the bulbus (Figs 4D, 5C), moderately long RTA with blunt tip (Figs 4D-E, 5C-D; Caleb \& Mathai 2014) and embolus originating from the upper-lateral part of the bulbus. Brancus muticus Simon, 1902 might be related to B. calebi sp. nov. However, B. calebi sp. nov. can be distinguished by its finger-shaped membranous outgrowth and blunt tipped RTA (see Discussion for details).

\section{Etymology}

Named after our colleague T.D. John Caleb, the original discoverer of this species.

\section{Material examined}

\section{Holotype}

SRI LANKA: §ิ, North Western Province, Kurunagala District, Ethagala, hand collection, 28 Jul. 2007, Z. Jaleel leg. (IFS_SAL 675).

\section{Description}

Male

Measurements. TL 4.38, PL 2.10, PW at PLEs 1.50, AL 2.25, AW 1.80. Eye field: diameter of AME 0.60, PLE 0.15, ALE 0.30, PME 0.03, PME-PME 1.35, PLE-PLE 1.45, ALE-PME 0.46, ALE-PLE 0.58. Leg I: Tr 0.35, Fm 1.15, Pt 0.55, Tb 1.00, Mt 0.65, Ta 0.50; Leg II: Tr 0.30, Fm 1.20, Pt 0.50, Tb 0.90, Mt 0.53, Ta 0.50; Leg III: Tr 0.35, Fm 1.35, Pt 0.55, Tb 0.65, Mt 0.80, Ta 0.60; Leg IV: Tr 0.40, Fm 1.35, Pt 0.65, Tb 1.00, Mt 0.65, Ta 0.65. 

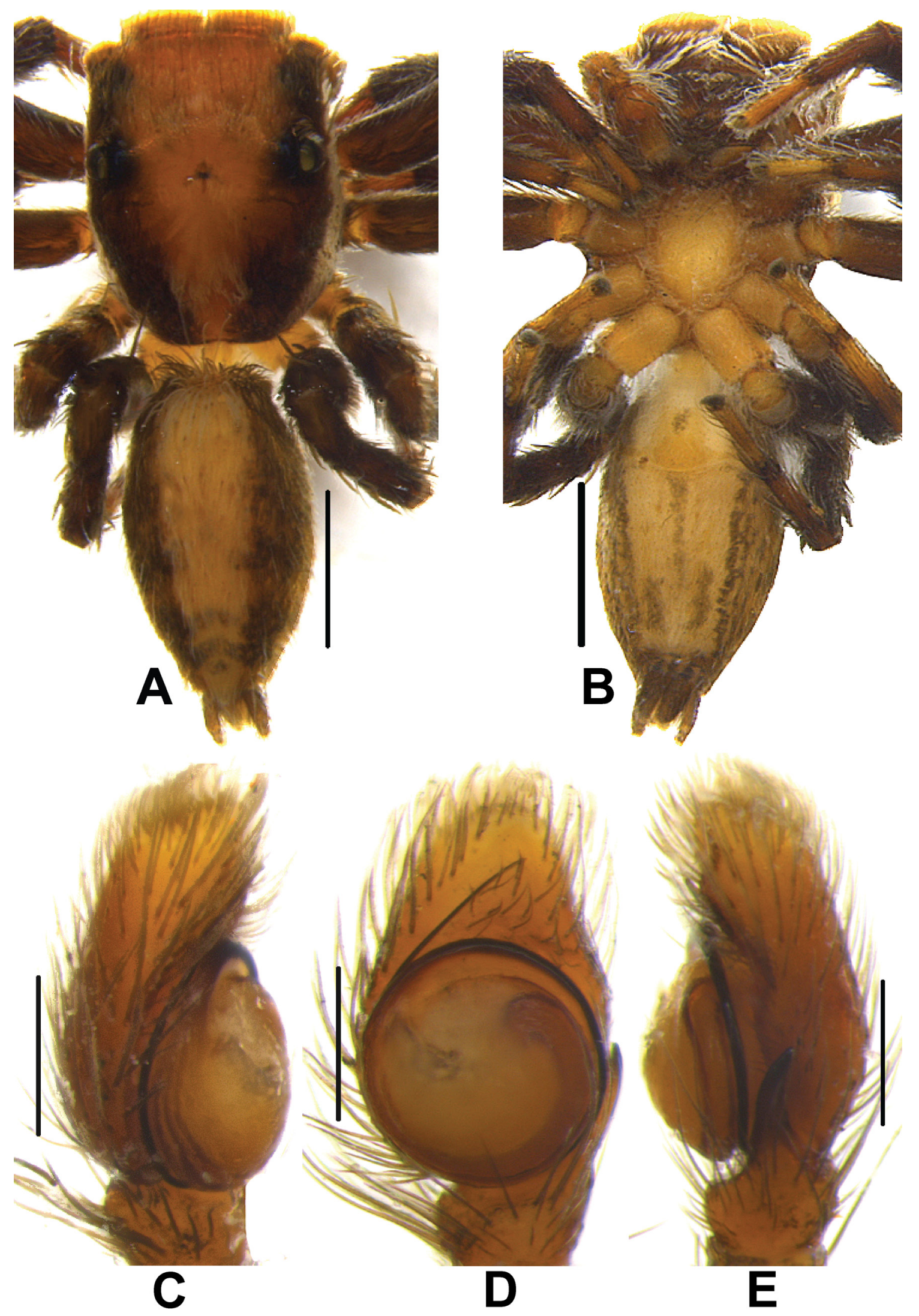

Fig. 4. Brancus calebi sp. nov., §. A. Habitus, dorsal view. B. Habitus, ventral view. C. Palp, prolateral view. D. Palp, ventral view. E. Palp, retrolateral view. Scale bars: $A-B=1 \mathrm{~mm}$; $-\mathrm{E}=0.2 \mathrm{~mm}$. 

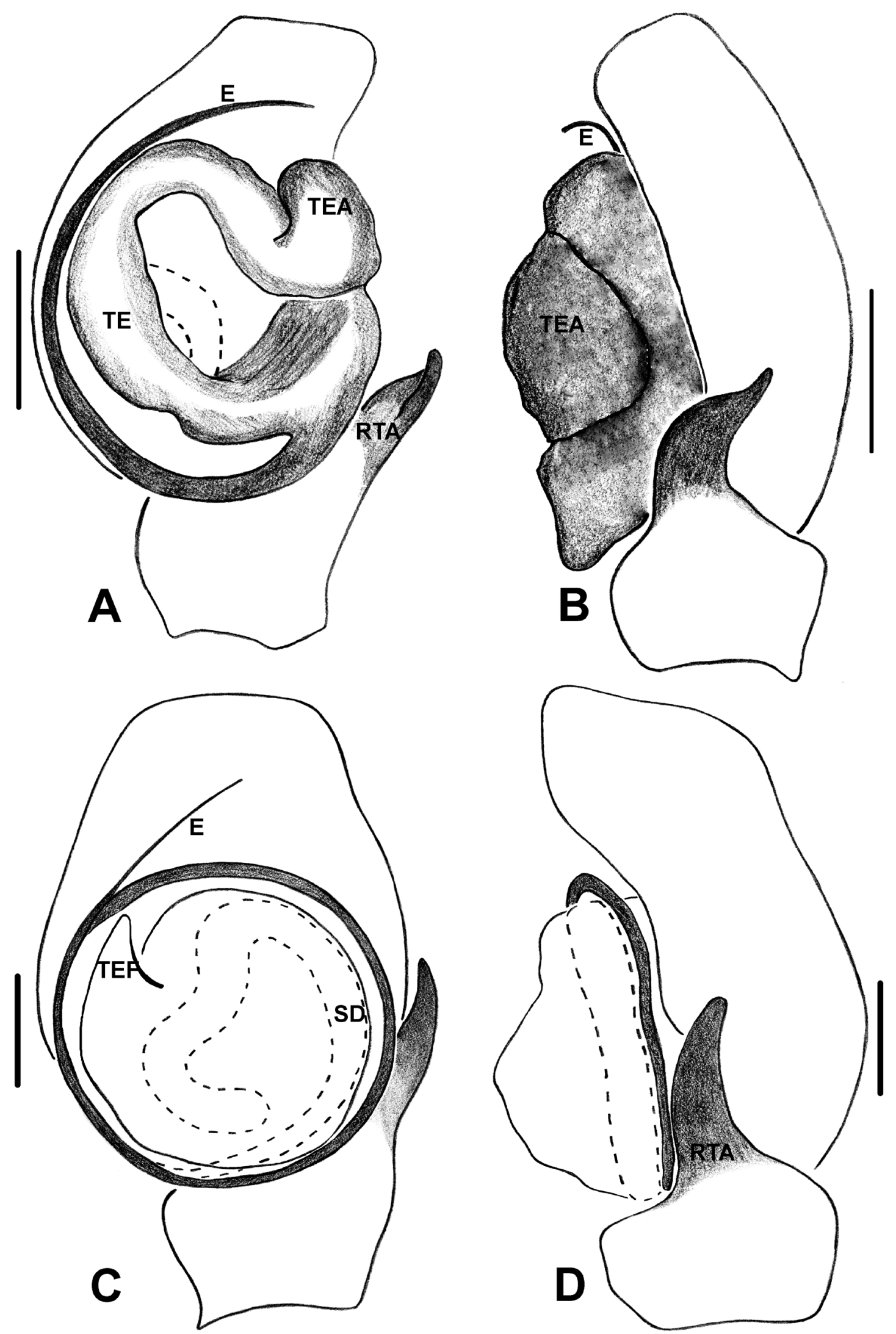

Fig. 5. A-B. Mogrus frontosus Simon, 1871, đ̂. C-D. Brancus calebi sp. nov., đ̃. A, C. Palp, ventral view. B, D. Palp, retrolateral view. Abbreviations: see Material and methods. Scale bars: $0.2 \mathrm{~mm}$. 
COLOR AND BODY. Oval shaped prosoma with orange pale-yellow posterior median band extending laterally above PLEs (Fig. 4A). A pair of brown stripes run from edge of eye field to posterior margin of cephalothorax. Lateral prosoma covered with tuft of pale yellow scales. Anterior eyes surrounded by white scales anteriorly and reddish orange scales posteriorly, clypeus reddish brown, covered with stripes of white scales. Fovea indistinct. Chelicerae reddish black, with 2 promarginal and 1 retromarginal tooth with bifurcated tip (Caleb \& Mathai 2014). Sternum oval in shape. Posterior prosoma rather steep and its margin slightly truncated. Legs dark brown, enclosed with spines, other than pale brown metatarsus and tarsus. Abdomen dark brown and elongated oval-shaped. Dorsum decorated with a greyish yellow longitudinal median band densely covered with fine grey-white hairs (Fig. 4A); three or four chevrons posteriorly extending from anterior to spinnerets. Venter yellowish brown with brown longitudinal markings in preserved specimens (Fig. 4B). Lateral abdomen dark brown along its length. Spinnerets dark brown.

PALP. Brown with reddish brown cymbium. Cymbium shorter and narrower at distal region. Thin and very long embolus originating perpendicular to bulbus at anterolateral position and encircling bulbus completely in one circle (Figs 4C-E, 5C-D). Bulbus rounded, with small, finger-shaped and membranous flap-like structure on anterolateral position of bulbus (Figs 4D, 5C). Spermatophore loop clearly visible at antero-retrolateral portion of bulbus and running along outline of bulbus. RTA moderately long, broader at the base and bent dorsally, with blunt tip (Figs 4D-E, 5C-D).

\section{Distribution}

India, Sri Lanka.

Genus Mogrus Simon, 1882

\section{Type species}

Mogrus fulvovittatus Simon, 1882, by monotypy.

\section{Diagnosis}

Body densely covered with long and narrow scales with marginal spines (Logunov 1995). Prosoma with elevated and broader ocular field. Posterior prosoma steeper. Chelicerae with two fused promarginal and one retromarginal tooth (Andreeva et al. 1981). Oval abdomen with a dark, median serrated longitudinal band in males. Palp with narrowed and curved cymbium. RTA moderately long, slightly curved apically, shape variable. Embolus originating perpendicularly to bulbus, bending and running parallel to bulbus margin (Prószyński 2016). Pars pendula and truncus well-developed (Logunov 1995: figs 4, 43). Distal sclerite of embolus easily visible and distal hematodocha connected to terminal apophysis (Logunov 1995: figs 41-43). Bulbus broad oval or nearly rounded, with striking lateral or basal protuberance (Andreeva et al. 1981; Prószyński 2016). Sperm duct broad and simple. Epigyne oval, with a pair of narrow subparallel depressions in the anterior half connected anteriorly and resembling a horseshoe, with copulatory openings at their posterior end (Logunov 1995; Prószyński 2016). Broad and membranous insemination ducts, rounded sac-like spermathecae with thick walls. Conspicuous, short accessory glands.

\section{Distribution}

Africa, Asia, Europe. 
Mogrus frontosus Simon, 1871

Figs $5 \mathrm{~A}-\mathrm{B}, 6-7$

\section{Diagnosis}

This species can be distinguished from its congeners by the broad RTA with a dorsally curved small tip (Figs 5A-B, 7D-E). It is closely related to M. antoninus Andreeva, 1976 (Andreeva 1976). However, it differs by the relatively shorter RTA with dorsally curved prominent tip and the position of the protrusion of the bulbus (Figs 5A-B, 7C-E).

\section{Material examined}

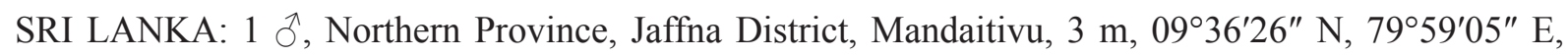
beating, 20-22 Sep. 2016, Benjamin et al. leg. (IFS_SAL 956).
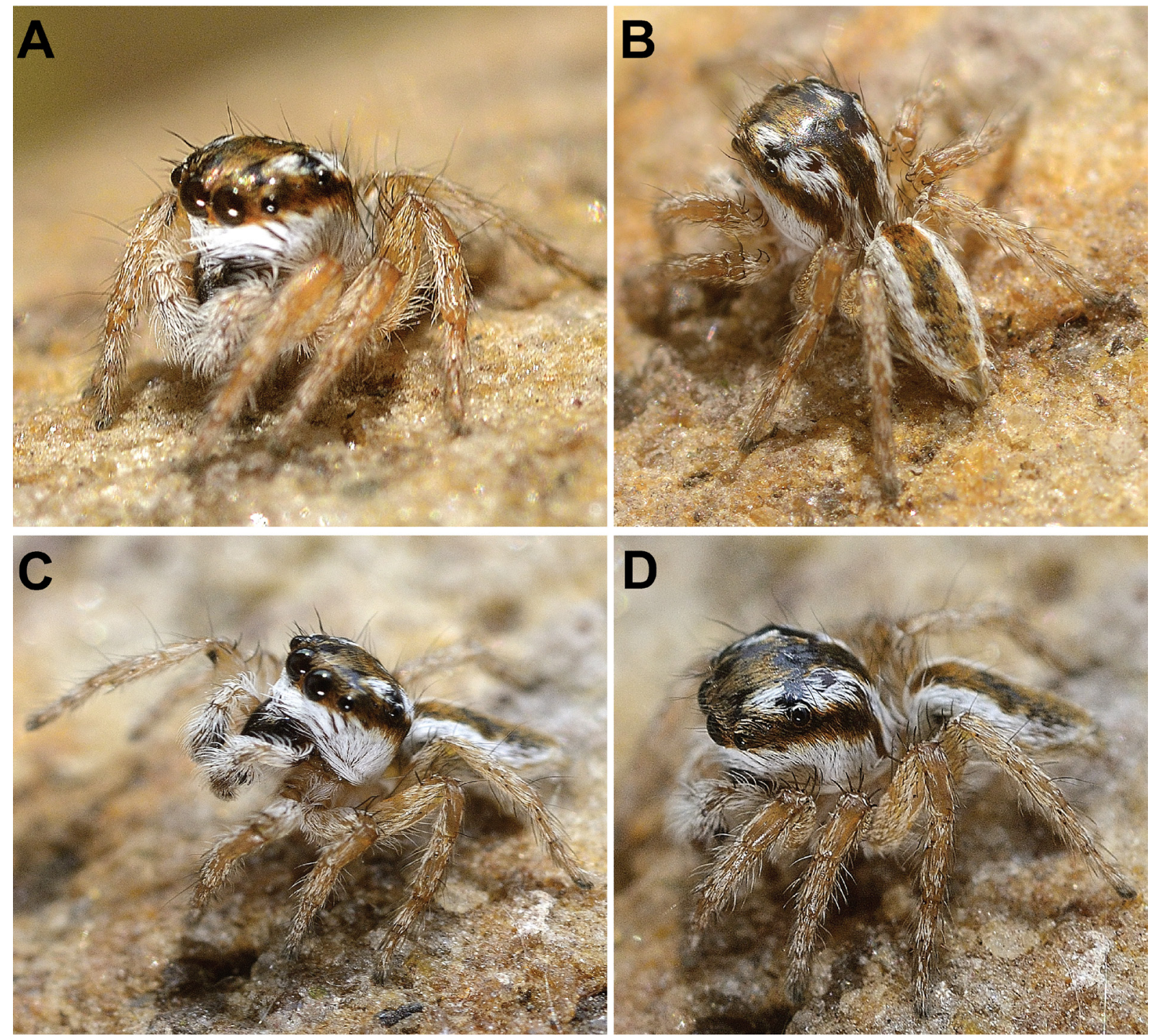

Fig. 6. Mogrus frontosus Simon, 1871. A-D. Male in life from Mandaitivu, Jaffna. 

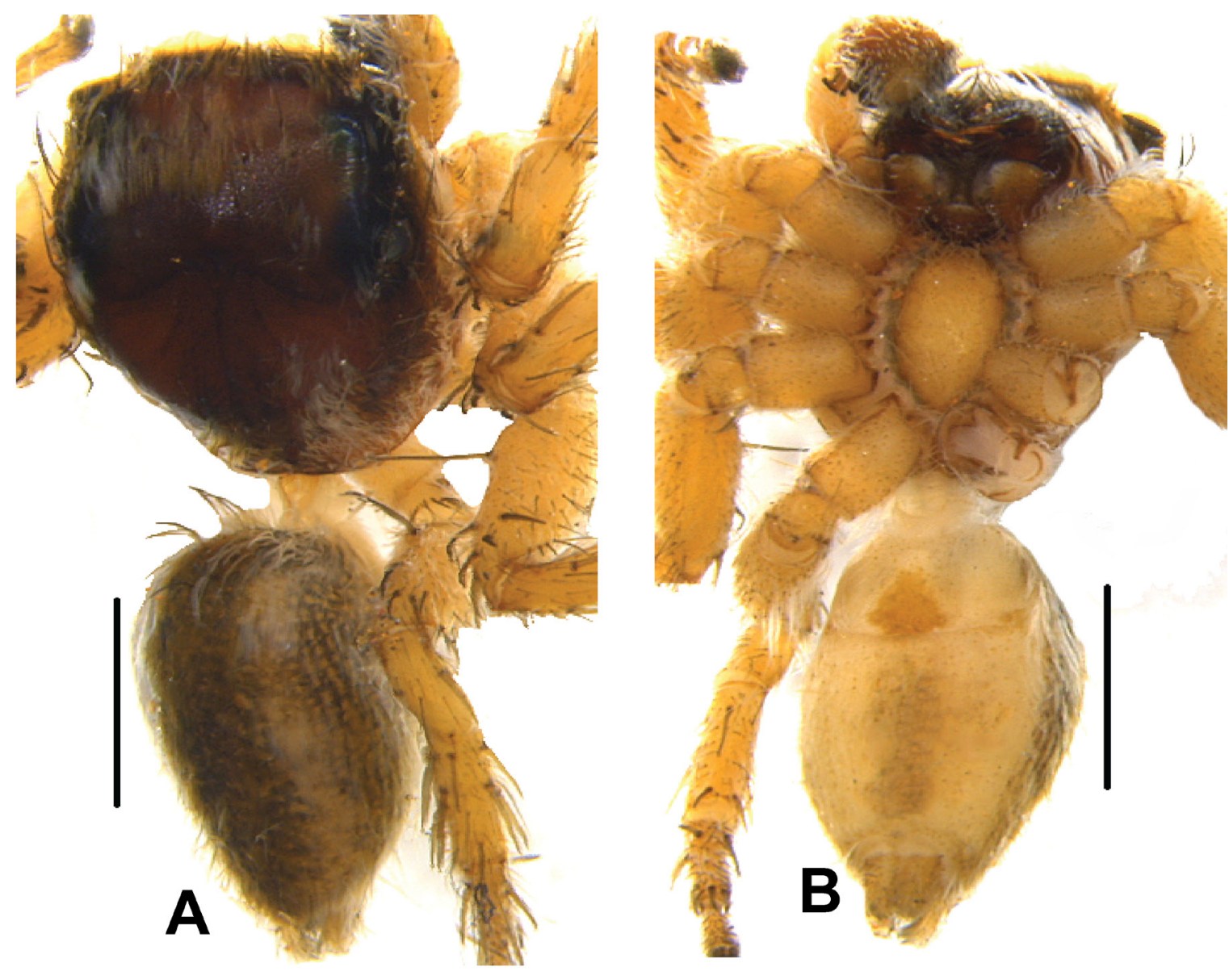

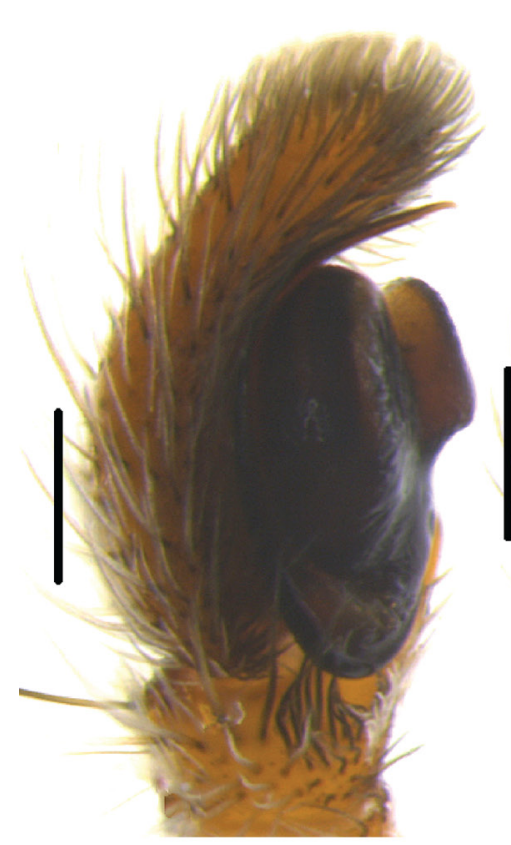

C

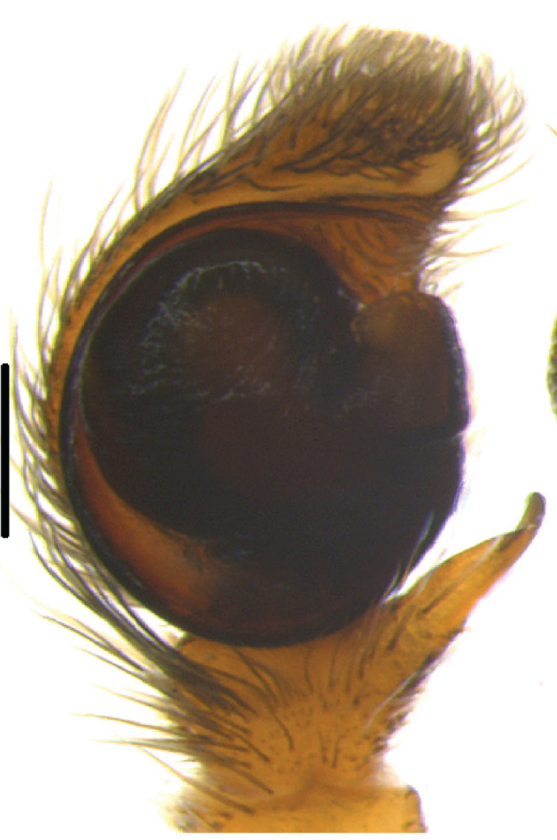

D

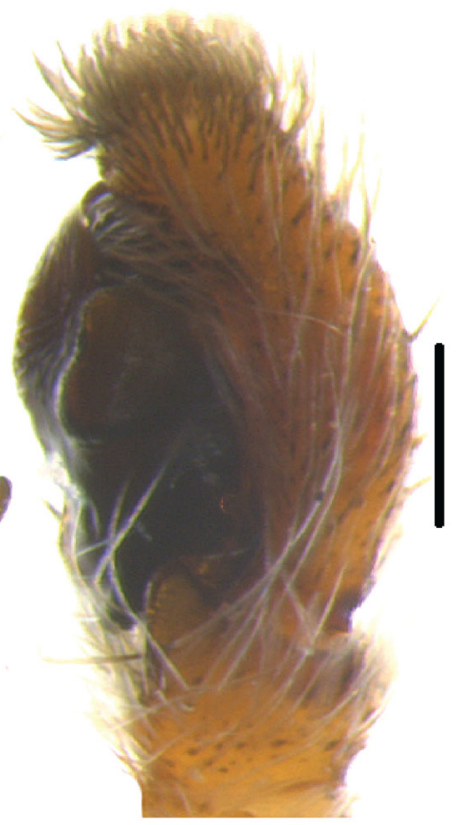

$\mathbf{E}$

Fig. 7. Mogrus frontosus Simon, 1871, đ̃. A. Habitus, dorsal view. B. Ventral view. C. Palp, prolateral view. D. Palp, ventral view. E. Palp, retrolateral view. Scale bars: $A-B=1 \mathrm{~mm}$; $-E=0.2 \mathrm{~mm}$. 


\section{Description}

\section{Male}

Measurements. TL 4.54, PL 2.40, PW at PLEs 1.85, AL 2.10, AW 1.70. Eye field: diameter of AME 0.55, PLE 0.17, ALE 0.35, PME 0.03, PME-PME 1.30, PLE-PLE 1.42, ALE-PME 0.45, ALE-PLE 0.60. Leg I: Tr 0.30, Fm 1.20, Pt 0.65, Tb 1.10, Mt 0.58, Ta 0.55; Leg II: Tr 0.28, Fm 1.25, Pt 0.55, Tb 0.92, Mt 0.50, Ta 0.57; Leg III: Tr 0.30, Fm 1.38, Pt 0.58, Tb 0.60, Mt 0.87, Ta 0.63; Leg IV: Tr 0.30, Fm 1.25, Pt 0.68, Tb 1.00, Mt 0.64, Ta 0.61.

Color AND BODy. In life, clypeus covered with tuft of long white scales (Fig. 6A, C). Brown prosoma covered with pale white and yellowish brown hairs and lateral prosoma with broad white bands (Fig. 6AD). Chelicerae and labium black in colour. Anterior prosoma narrower than posterior region. Ocular field slightly raised. PMEs and PLEs surrounded by black blotches. Fovea distinct. In preserved specimens, brown prosoma interspersed with grey hairs, posterior prosoma decorated with black stripe pattern (Fig. 7A), steeper and its margin slightly truncated. Sternum yellowish brown and oval in shape, edges bordered with brown colour (Fig. 7B). Legs yellowish brown. Abdomen slightly longer and narrower than prosoma, tapering posteriorly. Dorsum pale white, with yellowish brown longitudinal, median, serrated stripe with black dots from anterior to posterior end (Fig. 6B-D). Venter yellowish brown with blackish grey median marking. Spinnerets yellowish brown.

PALP. Yellowish brown palp with brown cymbium. Cymbium short and narrower at distal region. Thin and long embolus originating perpendicular to bulbus and bending parallel to it in a semicircle (Figs 5A, 7C-D). Bulbus irregular oval, with prominent protuberance on retrolateral position of bulbus above point of origin of embolus (Figs 5A-B, 7D-E; Andreeva et al. 1981). RTA moderately long, broader at the base and bent dorsally at the tip (Figs 5A-B, 7D-E).

\section{Female}

Unknown

Genus Schenkelia Lessert, 1927

\section{Type species}

Schenkelia modesta Lessert, 1927, by monotypy (Lessert 1927).

\section{Diagnosis}

Prosoma with black and slightly elevated eye field. Chelicerae with a bifid tooth on the inner posterior margin and two simple teeth on the inner anterior margin. Ovoid, tapered abdomen, almost as long as prosoma. Palp with an oval bulbus and with very conspicuous posterior and apical lobe. Embolus broad based, short and robust. Cymbium short. RTA thin and undulating, with sclerotized process or bifurcated. The anterior dorsal edge of the palpal tibia with rounded flaps (Prószyński 1968). Epigyne a simple pair of semicircular depressions, leading to the copulatory openings. Copulatory ducts are not discernible. Spermathecae gobular, with thick walls. See Prószyński (1968) for a detailed description of the type species.

\section{Distribution}

Africa, Sri Lanka. This is the first record of Schenkelia outside of Africa 


\section{Schenkelia aurantia sp. nov. urn:lsid:zoobank.org:act:D94B654F-196A-4B3C-92CC-160EECDFFEC6}

Figs 8-11

\section{Diagnosis}

This species is rather similar to $S$. modesta Lessert, 1927 in the shape of the bulbus and ALT, short embolus in males, and presence of sclerotized atria and lack of CD in females. However, it can readily be distinguished from the latter by the shape of the posterior lobe of the bulbus, comparably shorter ALT and bifurcated RTA in males (Figs 9D-E, 10A-B), and shape of the atria, double chambered spermathecae and shape of FD (Figs $10 \mathrm{C}-\mathrm{D}, 11 \mathrm{C}-\mathrm{D}$ ) in females.

\section{Etymology}

The specific epithet is derived from the Latin term 'aurantia' and refers to the orange-coloured markings around PLEs and PMEs.

\section{Material examined}

Holotype

SRI LANKA: $\hat{0}$, North Central Province, Anuradhapura District, Mihintale Sanctuary, $300 \mathrm{~m}$, $08^{\circ} 21^{\prime} 02.14^{\prime \prime} \mathrm{N}, 8^{\circ} 031^{\prime} 01^{\prime \prime}$ E, beating, 6 Jul. 2013, SP. Benjamin et al. leg. (IFS_SAL_302).

\section{Paratype}

SRI LANKA: 1 + , same collection data as for holotype (IFS_SAL_304).

\section{Other material}

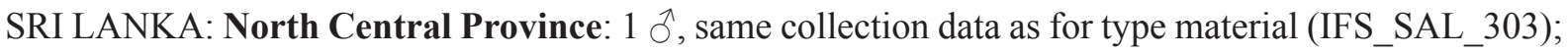
2 đิㅅ, 2 우, same collection data as for type material, but 20 May 2013, I. Sandunika et al. leg.

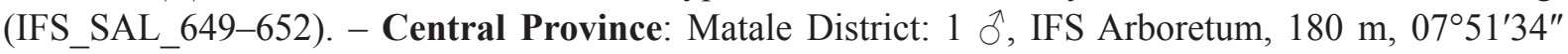

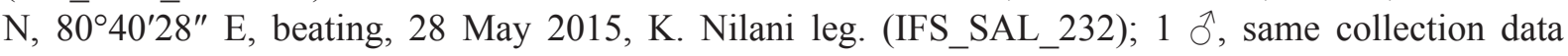
as for preceding, but 7 Jul. 2013, S.P. Benjamin \& N. Athukorala leg. (IFS_SAL_303); 1 त, same collection data as for preceding, but 17 Aug. 2012, S.P. Benjamin et al. leg. (IFS_SAL_437); 2 우우, same collection data as for preceding, but 19 Oct. 2015, K. Nilani leg. (IFS_SAL_544-545). - North Western Province: Kurunagala District: 1 o, Nikaravatiya, 1-3 Feb. 2007, hand collecting, Z. Jaleel leg. (IFS_SAL_077); 1 क, Ethagala, 13 May 2007, hand collection, Z. Jaleel leg. (IFS_SAL_332). Western Province: Gampaha District: 1 o, Kadol Kale, mangrove forest, $07^{\circ} 11^{\prime} 49^{\prime \prime}$ N, 79 $50^{\prime} 35^{\prime \prime}$ E, litter, 24 Sep. 2014, N. Athukorala leg. (IFS_SAL_333).

\section{Description}

Male

Measurements. TL 3.8, PL 1.85, PW at PLEs 1.4, AL 1.75, AW 1.10. Eye field: diameter of AME 0.39, PLE 0.18, ALE 0.22, PME 0.04, PME-PME 1.17, PLE-PLE 1.01, ALE-PME 0.27, ALE-PLE 0.47. Leg I: Tr 0.30, Fm 1.00, Pt 0.5, Tb 0.75, Mt 0.50, Ta 0.40; Leg II: Tr 0.35, Fm 1.00, Pt 0.50, Tb 0.60, Mt 0.50, Ta 0.40; Leg III: Tr 0.30, Fm 1.25, Pt 0.60, Tb 0.75, Mt 0.75, Ta 0.40; Leg IV: Tr 0.32, Fm 1.00, Pt 0.55, Tb 0.70, Mt 7.75, Ta 0.4.

COLOR AND BODY. In preserved specimens, prosoma brown in colour, longer than wide. Ocular area black with a broad impression between PLEs. Dark black transversal stripe on posterior prosoma (Fig. 9A). Fovea indistinct. Posterior prosoma much steeper and its margin slightly truncated. Sternum yellowish brown and oval in shape, edges bordered with brown colour (Fig. 9B). Legs brownish yellow and with dark brown banding patterns. Abdomen ovoid, slightly shorter and narrower than prosoma, tapering 
posteriorly (Fig. 9A-B). Dorsum blackish brown, ornamented with two yellowish brown transversal bands on anterior abdomen and irregular blotches on posterior half (Fig. 9A). Venter yellowish brown with brownish black lateral markings and irregular blotches at posterior end (Fig. 9B). Spinnerets yellowish brown.

PaLp. Yellowish brown. Cymbium shorter and narrower at distal region. Embolus short, curved retrolaterally and immovable on apical portion of bulbus. Bulbus nearly rounded, with well-developed posterior lobe and broadened sperm duct. Spermatophore loop clearly visible at antero-lateral portion of bulbus. Mid-tegulum with small irregular posterior lobe. RTA bifurcated, with two branches of unequal in size, one moderately long and curved at tip, the other short and pointed.

\section{Female}

MeAsurements. TL 2.5, PL 1.15, PW at PLEs 0.90, AL 1.20, AW 0.80. Eye field: diameter of AME 0.52, PLE 0.20, ALE 0.27, PME 0.04, PME-PME 1.44, PLE-PLE 1.26, ALE-PME 0.40, ALE-PLE 0.63. Leg I: Tr 0.28, Fm 0.65, Pt 0.65, Tb 0.75, Mt 0.50, Ta 0.30; Leg II: Tr 0.30, Fm 0.60, Pt 0.60, Tb 0.60, Mt 0.50, Ta 0.40; Leg III: Tr 0.30, Fm 0.80, Pt 0.60, Tb 0.75, Mt 0.75, Ta 0.50; Leg IV: Tr 0.35, Fm 0.65, Pt 0.50 , Tb 0.75, Mt 0.75, Ta 0.50 .
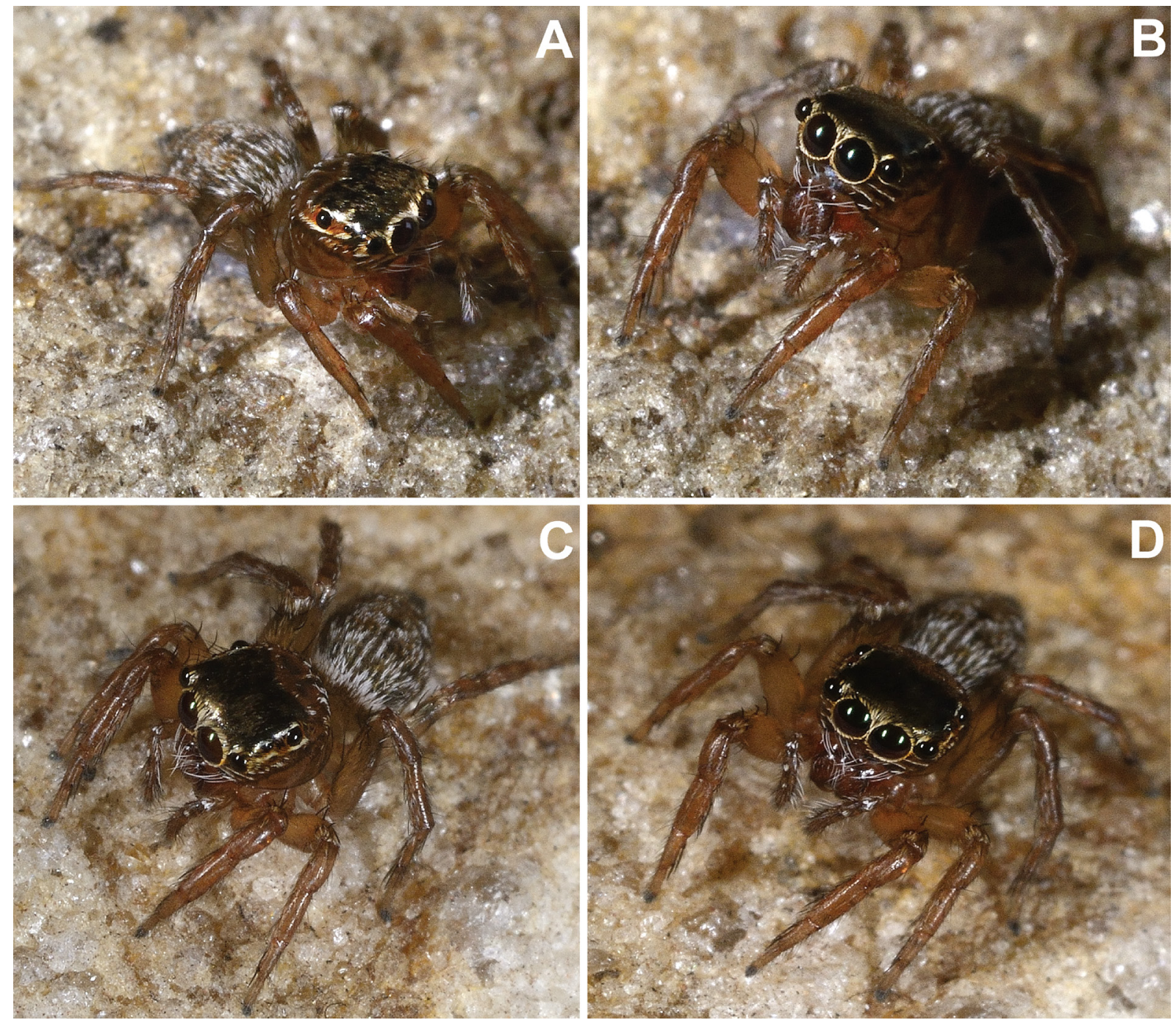

Fig. 8. Schenkelia aurantia sp. nov. A-D. Female in life from IFS Arboretum, Dambulla. 


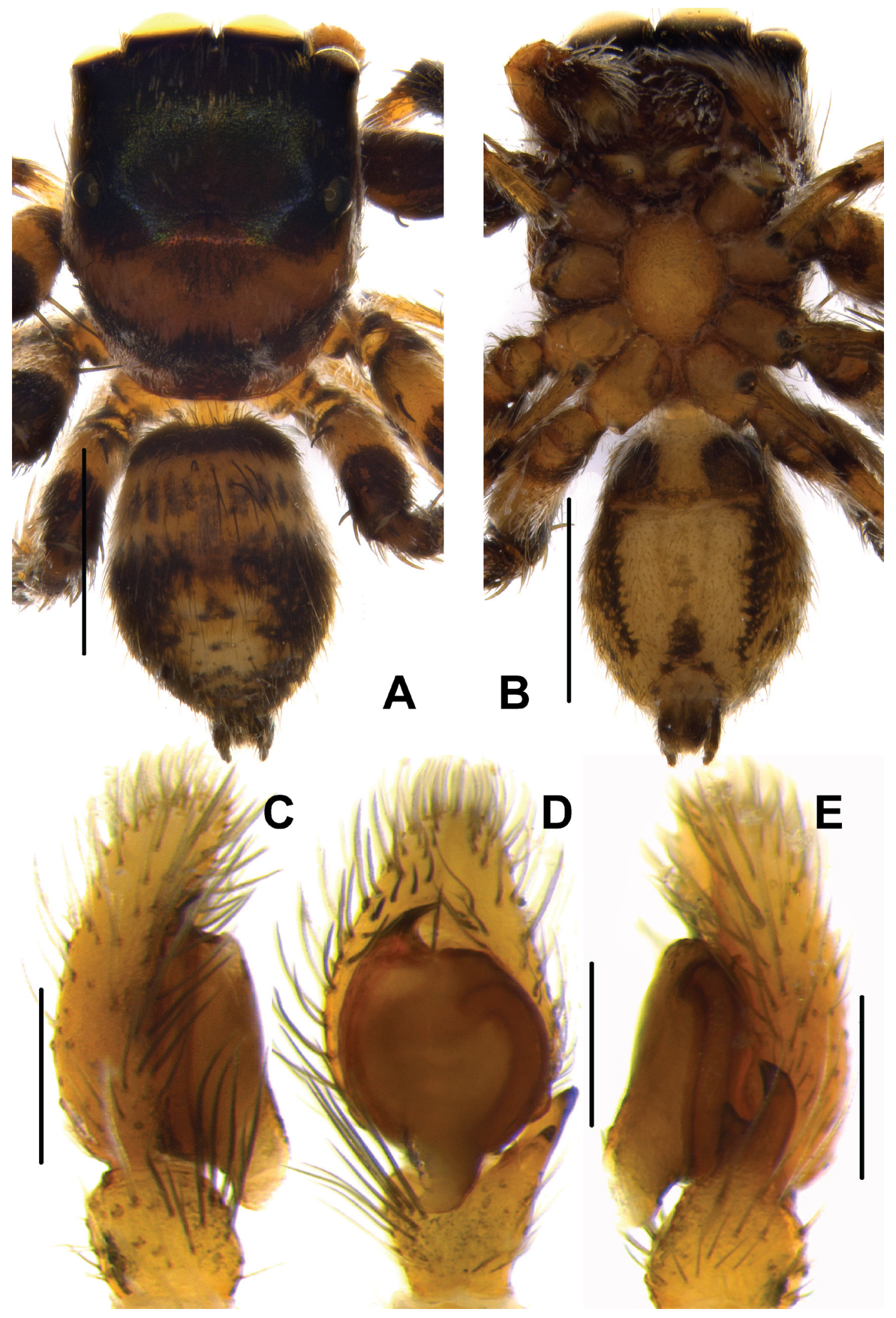

Fig. 9. Schenkelia aurantia sp. nov., ठ̂. A. Habitus, dorsal view. B. Habitus, ventral view. C. Palp, prolateral view. D. Palp, ventral view. E. Palp, retrolateral view. Scale bars: A-B $=1 \mathrm{~mm} ; \mathrm{C}-\mathrm{E}=0.2 \mathrm{~mm}$. 

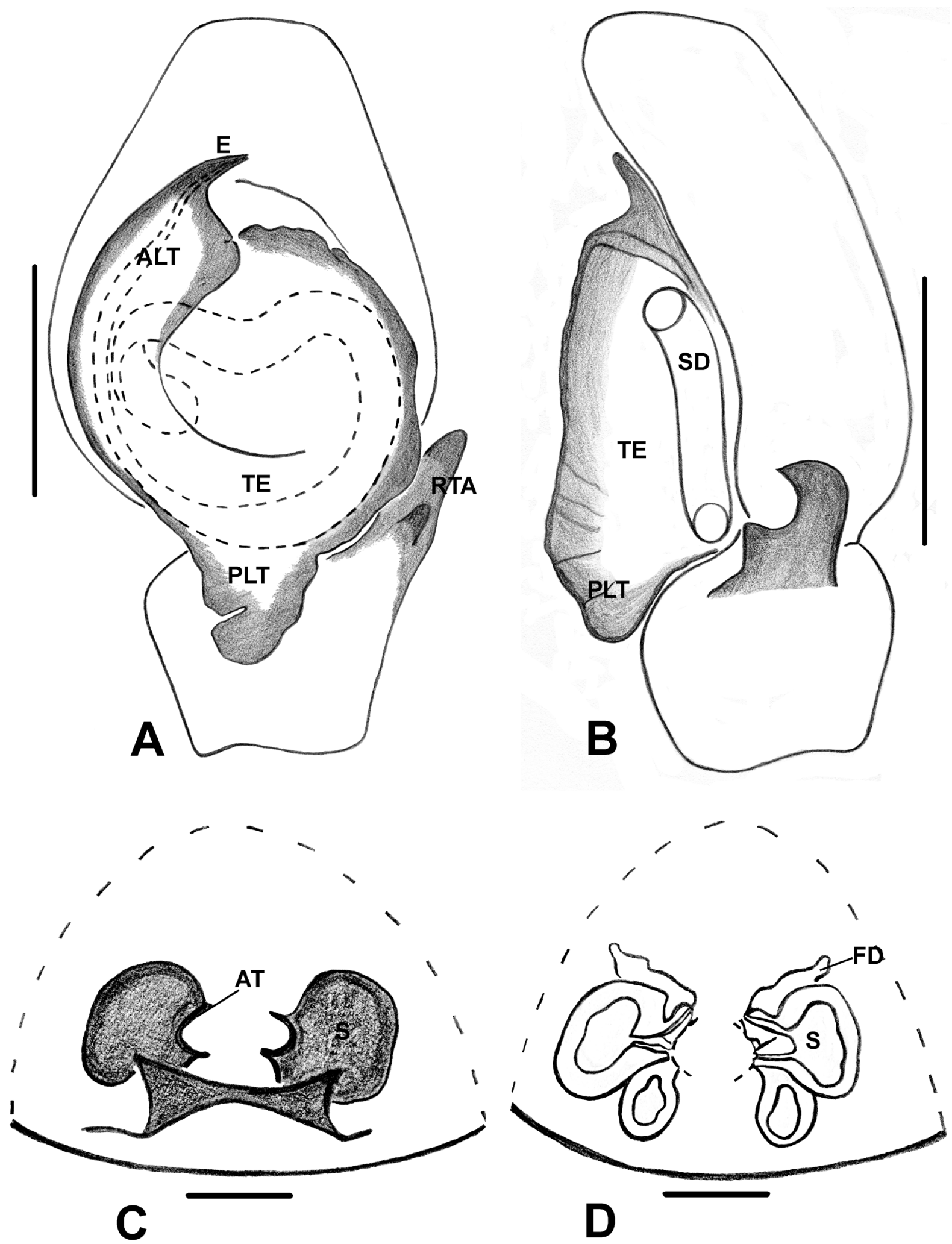

Fig. 10. Schenkelia aurantia sp. nov. A. Palp, ventral view. B. Palp, retrolateral view. C. Epigyne, ventral view. D. Vulva, ventral view. Abbreviations: see Material and methods. Scale bars: A-B = $0.2 \mathrm{~mm} ; \mathrm{C}-\mathrm{D}=0.1 \mathrm{~mm}$. 

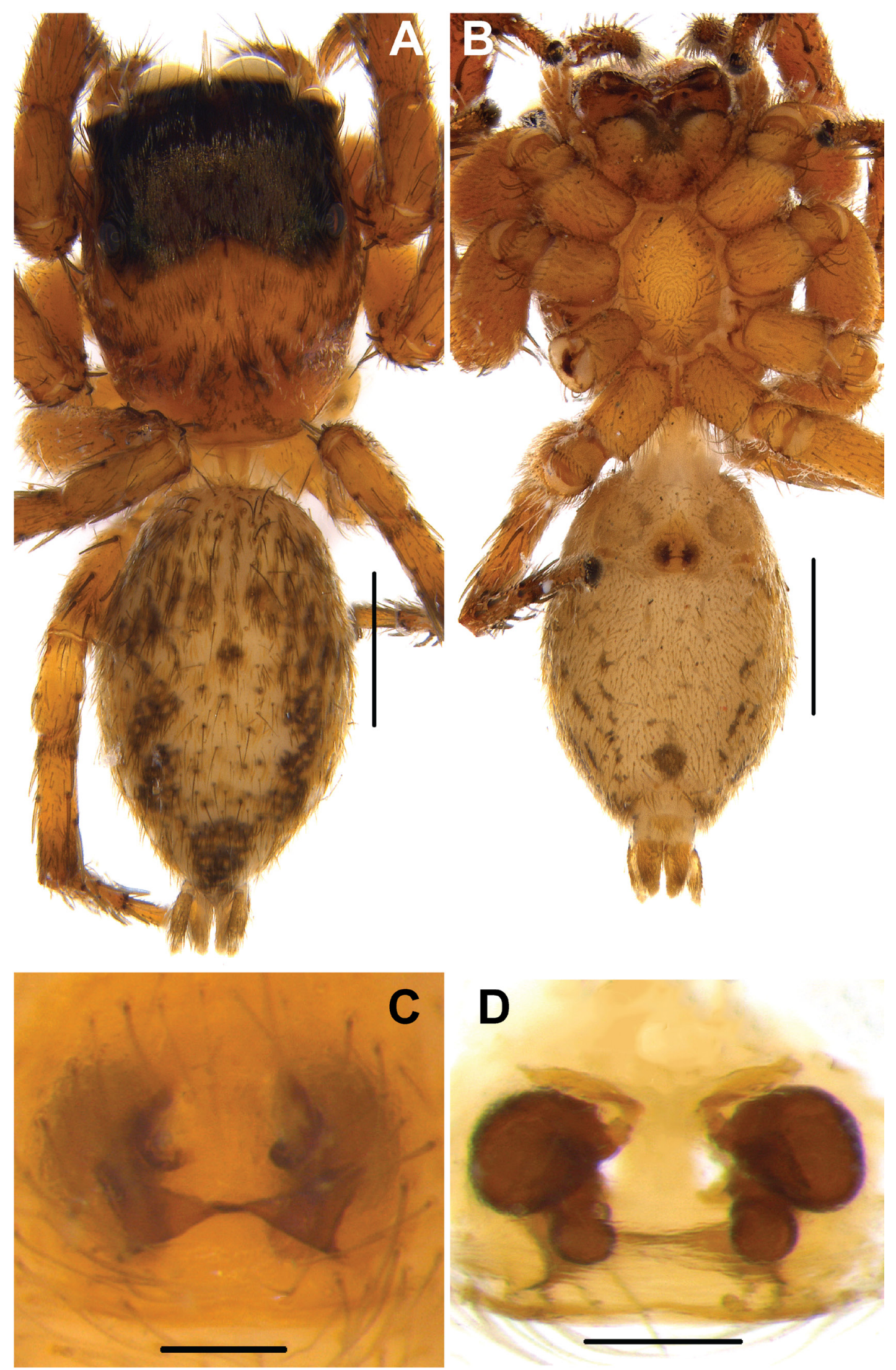

Fig. 11. Schenkelia aurantia sp. nov., ․ . A. Habitus, dorsal view. B. Habitus, ventral view. C. Epigyne, ventral view. D. Vulva, ventral view. Scale bars: A-B $=1 \mathrm{~mm}$; $C-D=0.1 \mathrm{~mm}$. 
COLOR AND BODY. In life, chelicerae blackish brown, clypeus narrowed (Fig. 8B, D). Prosoma yellowish brown with white markings and blackish brown stripe pattern on posterior region (Fig. 8A, C). Ocular field glossy black and slightly raised. AMEs and ALEs enclosed with pale yellow scales. PLEs and PMEs covered with yellowish orange and pale white patches laterally (Fig. 8A, C). Chelicerae and labium pale brown in colour. Light brown legs. Abdomen slightly shorter and broader than prosoma, tapering posteriorly. Dorsum brownish grey, decorated with irregular greyish white and black patches and anterior margin of abdomen covered with tuft of white scales (Fig. 8A-D). In preserved specimens, venter yellowish brown with unevenly distributed, irregular dark grey patches (Fig. 11B). Other characters as in males.

EPIGYNUm. Moderately sclerotized. Gamma-shaped atria on the anterior margin through which CO opens (Figs 10C, 11C). CD is absent, hence CO directly leading into narrowed region of large chamber of receptacles. Spermathecae double chambered and sclerotized, with thick wall (Figs 10D, 11D). FD originates from anterolateral portion of large chamber (Figs 10C-D, 11C-D). At posterior border, two lateral unusual pocket-like structures (Figs 10C, 11C).

\section{Discussion}

Bavirecta flavopuncta gen. et sp. nov. was provisionally placed in the genus Bavia, based on its superficially similar habitus (Cao et al. 2016). However, it differs considerably from the type species of the genus Bavia, B. aericeps, by the presence of the long RTA, the broader posterior lobe of the tegulum with black blotches, the relatively longer and narrower copulatory ducts, the pear-shaped spermathecae, and the absence of a mid-posterior projection on the epigynum (very short RTA, compact and wider CD, midposterior projection in B. aericeps; see Berry et al. 1997). However, although most current members of Bavia are somatically very similar, their genitalia differ considerably, displaying an enormous diversity in the genital structures (Maddison 2015; Prószyński 2016; Prószyński \& Deeleman-Reinhold 2013). Thus, most probably, Bavia is polyphyletic and in urgent need of taxonomic attention. Nevertheless, Bavirecta flavopuncta gen. et sp. nov. and B. exilis gen. et comb. nov. could clearly be recognized as evolutionarily distinct, warranting the erection of a new genus. Further, Maddison (2015) stated that members of the tribe Baviini share consistent plesiomorphic characters (elongated and flattened body form and typical oval palp with fixed embolus) with possibly related marpissines and viciriines, but without any unambiguous synapomorphies to delimit baviines.

The genera Brancus and Thyene are included in the tribe Plexippini, subtribe Plexippina due to the shared presence of a round bulb and the simple, fixed embolus. However, there are no known synapomorphies in support of this grouping (Maddison 2015). Brancus differs considerably from T. bivittata, as well as from other Thyene, by the following characters of the latter as follows: shape flatter, more elongate (compact in Brancus calebi sp. nov. and in other Brancus), prosoma much broader at the third eye row (oval in Brancus), robust first pair of legs (slightly enlarged in Brancus) and presence of a pair of lateral tufts of hairs near PMEs (absent in Brancus). Furthermore, some species classified in Thyene, including Thyene bivittata, differ from the type species $T$. imperialis (Rossi, 1846) especially by their habitus. Brancus calebi sp. nov. closely resembles other species of Brancus, including the type species B. muticus, in palpal morphology as well as habitus. The discovery of females may further corroborate our generic placement, as species of both genera differ considerably by the internal epigynal structures (presence of a rectangular membranous window, coiled membranous ducts, multi-chambered receptacles in Thyene, against anterior depression, simple oval or bent spermathecae in Brancus; see Prószyński 2016). African Brancus spp and Asian Telamonia spp might seem similar due to their palpal structures, especially due to the presence of a flap on the bulbus. However, Asian Telamonia differ by their general habitus, the absence of the midpoint retrolateral expansion of the cymbium, the characteristic bunch of long, stiff setae at the same midpoint expansion of the cymbium and the internal structure of the epigyne (Prószyński 2016). 
So far, four species of Schenkelia are known to science (World Spider Catalog 2018). Although there are some differences with the type species $S$. modesta (the absence of a thread-like, long RTA and the structure of the spermathecae), our specimens are placed in Schenkelia because of the similarities in habitus, palpal and internal epigynal structures. This placement is further corroborated by our unpublished molecular data: the $28 \mathrm{~S}$ sequence of S. aurantia sp. nov. is sister to the sequence of Schenkelia modesta obtained from GenBank (accession \# EU815487.1).

\section{Conservation status}

Bavirecta flavopuncta gen. et sp. nov. is known from relatively few individuals and is restricted to high altitude forest $(600-1300 \mathrm{~m})$ in the Central Province of Sri Lanka. The known localities are within protected areas. However, they are increasingly threatened due to woodcutting of old trees for timber, fire wood collection, cultivation of vegetables/cardamom and simple vandalism. Climate change may pose a further threat to this endemic species. Assessment against the IUCN criteria (IUCN 2001) results in a status of vulnerable 'VU D1'. This assessment is based on an estimated population of less than 1000 adult spiders.

\section{Acknowledgments}

Funding from the NIFS, the Alexander von Humboldt Foundation and a research grant from the National Research Council (\# 17-027) to SPB is thankfully acknowledged. We are indebted to R.M.G.N. Tilakarathna, P.M.H. Sandamali, S. Batuwita, Z. Jaleel, I. Sandunika and N. Athukorala for the collection of specimens used in this study. DWLC and DFC of Sri Lanka facilitated fieldwork. We thank students from the Rajarata University of Sri Lanka, I. Wijerathne, C. Priyadarshani and P. Panduwawala, for measuring the specimens of Schenkelia. Finally, yet importantly, we thank two anonymous reviewers for helpful comments.

\section{References}

Alvarez-Padilla F. \& Hormiga G. 2008. A protocol for digesting internal soft tissues and mounting spiders for scanning electron microscopy. Journal of Arachnology 35: 538-542.

Andreeva E.M. 1976. Payki Tadzhikistana. Dyushanbe.

Andreeva E.M., Kononenko A.P. \& Prószyński J. 1981. Remarks on genus Mogrus Simon, 1882 (Araneae, Salticidae). Annales Zoologici 36: 85-104.

Benjamin S.P. 2004. Taxonomic revision and phylogenetic hypothesis for the jumping spider subfamily Ballinae (Araneae, Salticidae). Zoological Journal of the Linnean Society 142: 1-82. https://doi.org/10.1111/j.1096-3642.2004.00123.x

Benjamin S.P. 2006. The male of Marengo nitida with the description of M. rattotensis new species from Sri Lanka (Araneae: Salticidae). Zootaxa 1326: 25-36.

Benjamin S.P. 2010. Revision and cladistic analysis of the jumping spider genus Onomastus (Araneae: Salticidae). Zoological Journal of the Linnean Society 159: 711-745.

https://doi.org/10.1111/j.1096-3642.2009.00580.x

Benjamin S.P. 2015. Model mimics: antlike jumping spiders of the genus Myrmarachne from Sri Lanka. Journal of Natural History 49: 3-44. https://doi.org/10.1080/00222933.2015.1034209

Benjamin S.P. \& Kanesharatnam N. 2016. Description of three new species of the tropical Asian jumping spider genus Onomastus Simon, 1900 from high altitude cloud forests of Sri Lanka (Araneae: Salticidae). Zootaxa 4205 (5): 431-453. https://doi.org/10.11646/zootaxa.4205.5.2 
Berry J.W., Beatty J.A. \& Prószyński J. 1997. Salticidae of the Pacific Islands. II. Distribution of nine genera, with descriptions of eleven new species. Journal of Arachnology 25: 109-136.

Caleb T.D. \& Mathai M.T. 2014. Description of some interesting jumping spiders (Araneae: Salticidae) from South India. Journal of Entomology and Zoology Studies 2: 63-71.

Cao X.W., Li S.Q. \& Żabka M. 2016. The jumping spiders from Xishuangbanna, Yunnan, China (Araneae, Salticidae). ZooKeys 630: 43-104. https://doi.org/10.3897/zookeys.630.8466

Dingerkus G. \& Uhler L.D. 1977. Enzyme clearing of alcian blue stained whole small vertebrates for demonstration of cartilage. Stain Technology 52: 229-232. https://doi.org/10.3109/10520297709116780

Edwards G.B. \& Benjamin S.P. 2009. A first look at the phylogeny of the Myrmarachninae, with rediscovery and redescription of the type species of Myrmarachne (Araneae: Salticidae). Zootaxa 2309: $1-29$.

IUCN. 2001. International Union for Conservation of Nature and Natural Resources. Species Survival Commission. IUCN Red List categories and criteria. Version 3.1 (Second edition).

Kanesharatnam N. \& Benjamin S.P. 2016. Three new generic records and descriptions of four new species of jumping spiders (Araneae, Salticidae) from Sri Lanka. European Journal of Taxonomy 228: 1-23. https://doi.org/10.5852/ejt.2016.228

Lessert R. 1927. Araignées du Congo (Première partie). Revue Suisse de Zoologie 34: 405-475. https://doi.org/10.5962/bhl.part.117612

Logunov D.V. 1995. The genus Mogrus (Araneae: Salticidae) of central Asia. European Journal of Entomology 92: 589-604.

Maddison W.P. 2015. A phylogenetic classification of jumping spiders (Araneae: Salticidae). Journal of Arachnology 43: 231-292. https://doi.org/10.1636/arac-43-03-231-292

Prószyński J. 1968. Redescriptions of the type-species of genera of Salticidae (Araneae), IV-V. Annales Zoologici 26: 217-225.

Prószyński J. 2016. Monograph of the Salticidae (Araneae) of the World 1995-2014. Chapter II: Global species database of Salticidae [online]. Available from http://www.peckhamia.com/salticidae/index.html [accessed 1 Jul. 2016].

Prószyński J. 2017. Pragmatic classification of the World's Salticidae (Araneae). Ecologica Montenegrina 12: $1-133$.

Prószyński J. \& Deeleman-Reinhold C.L. 2013. Description of some Salticidae (Araneae) from the Malay Archipelago. III. Salticidae of Borneo, with comments on adjacent territories. Arthropoda Selecta 22: 113-144.

Wesołowska W. \& Edwards G.B. 2012. Jumping spiders (Araneae: Salticidae) of the Calabar area (SE Nigeria). Annales Zoologici 62: 733-772. https://doi.org/10.3161/000345412x659786

Wesołowska W. \& Haddad C.R. 2013. New data on the jumping spiders of South Africa (Araneae: Salticidae). African Invertebrates 54: 177-240. https://doi.org/10.5733/afin.054.0111

Wesołowska W. \& Russell-Smith A. 2011. Jumping spiders (Araneae: Salticidae) from southern Nigeria. Annales Zoologici 61: 553-619. https://doi.org/10.3161/000345411x603409

World Spider Catalog. 2018. World Spider Catalog. Natural History Museum Bern, ver. 17.5. Available from http://wsc.nmbe.ch [accessed 2 Jan. 2018]. 
Manuscript received: 14 October 2017

Manuscript accepted: 18 January 2018

Published on: 14 June 2018

Topic editor: Rudy Jocqué

Desk editor: Kristiaan Hoedemakers

Printed versions of all papers are also deposited in the libraries of the institutes that are members of the EJT consortium: Muséum national d'Histoire naturelle, Paris, France; Botanic Garden Meise, Belgium; Royal Museum for Central Africa, Tervuren, Belgium; Natural History Museum, London, United Kingdom; Royal Belgian Institute of Natural Sciences, Brussels, Belgium; Natural History Museum of Denmark, Copenhagen, Denmark; Naturalis Biodiversity Center, Leiden, the Netherlands; Museo Nacional de Ciencias Naturales-CSIC, Madrid, Spain; Real Jardín Botánico de Madrid CSIC, Spain; Zoological Research Museum Alexander Koenig, Bonn, Germany. 